\title{
Changing trends in colorectal cancer: possible cause and clinical implications
}

\author{
Mikhail Fisher ${ }^{1}$, Leon Fisher ${ }^{2}$, Bruce Waxman ${ }^{1}$, Alexander A. Fisher ${ }^{3 *}$ \\ ${ }^{1}$ Academic Surgical Unit, Monash University, Dandenong Hospital, Southern Health, Melbourne, Australia \\ ${ }^{2}$ Department of Gastroenterology, Peninsula Health, Frankston, Australia \\ ${ }^{3}$ Division of Medicine, The Canberra Hospital and Australian National University Medical School, Canberra, Australia; \\ ${ }^{*}$ Corresponding Author: alex.fisher@act.gov.au
}

Received 18 April 2010; revised 4 May 2010; accepted 6 May 2010.

\begin{abstract}
OBJECTIVES: The aims of this study were to determine whether pattern of patients presenting with colorectal cancer (CRC) in the last few years differs significantly from that previously reported in Australia, and to relate the trends, if present, to use of hormone replacement therapy (HRT). METHODS: We examined demographic and pathological characteristics of 145 consecutive CRC patients (65 females) treated in our institution in calendar years 2006-2007. Comparisons were made with data on 12536 CRC patients obtained from the Australian Association on Cancer Registries (AACR) for the year 2003, most recent available. Prescribing data for HRT were obtained from the Australian Commonwealth Department of Health and Ageing. RESULTS: The distribution of colon, sigmoid and rectal cancers in our series was $40 \%$, $24.8 \%$ and $35.2 \%$, respectively, which differs significantly from $65 \%, 8.1 \%$ and $26.9 \%$ in the AACR data $(p<0.01)$. Our cohort was significantly younger (65.4 \pm 12.1 vs. $69.5 \pm 12.3$ years), especially females $(63.0 \pm 12.7$ vs. $70.3 \pm 13.0$ years; $p<0.001$ ). The proportion of female patients aged $<\mathbf{5 5}$ and $<\mathbf{6 0}$ years was significantly higher $(30.8 \%$ vs. $13.8 \%$ and $41.5 \%$ vs. $21.4 \%$, respectively). Younger patients have more aggressive and advanced cancers. In Australia HRT use declined since 2001 and fell by a half in 2006. CONCLUSIONS: In the changing CRC pattern of greatest concern is a significantly higher proportion of younger patients, especially females, with higher prevalence of more advanced and aggressive cancers, coincident with decreased prescribing of HRT. These findings may have important implications for refining
\end{abstract}

screening and preventive strategies and on demand for radiotherapy services.

Keywords: Colorectal Cancer; Age; Gender; Hormone Replacement Therapy; Trends

\section{INTRODUCTION}

Colorectal cancer (CRC) is the most prevalent non-skin malignancy and second highest cause of cancer-related death in Australia [1] as in other industrialized countries. The incidence and mortality increase with age and the risk of being diagnosed with CRC by age 85 years is one in 10 for males and one in 14 for females [1]. In the last two decades a decline in incidence and mortality rates for CRC has been observed in most developed countries including Australia [2-9]. The reasons for this trend may include risk factors modification, introduction of screening and improvements in medical intervention.

The characteristics of CRC vary significantly with age, gender, race/ethnicity and region of residence [7,10-12]. The causes for these differences, genetic, environmental or acquired, are not fully understood. Numerous epidemiological studies have suggested a protective effect of estrogens (alone or in combination with progestins) against CRC [13-18]. A meta-analysis of 18 observational studies of CRC and use of hormone replacement therapy (HRT) indicated a 34\% reduction among current users and a $20 \%$ reduction among ever users [19]. Similar data were reported in a large randomised controlled trial [20]. However, since the Women's Health Initiative (WHI) hormone trial demonstrated the risks of HRT (coronary heart disease, stroke, breast cancer, venous thromboembolism, cholecystitis), a sharp decline in the use of HRT has been seen over the last few years [21]. No study to date has addressed possible effects of reduced HRT use on CRC trends. 
In Australia, following a pilot program, national CRC screening program for people between 55 and 74 years of age is currently being phased in. However, the evidence in relation to target age is insufficient.

Better understanding of risk factors and regional trends, especially in relation to age, gender and anatomical site may prove invaluable in fine-tuning screening, providing better services and, perhaps, contribute to development of new preventative strategies. The purposes of the present study were 1) to determine whether pattern of patients presented with CRC to our institution in the last 2 years differs significantly from that previously reported in Australia in regard to age, gender, anatomical site, histopathology and TNM stage, and 2) to relate the trends, if present, to use of HRT.

\section{METHODS}

Study population consisted of 145 consecutive CRC patients (age ranged from 34 to 85 years, mean $65.4 \pm$ 12.13 years) treated in calendar years 2006 and 2007 in the Dandenong Hospital, a major public teaching hospital. The patients were admitted from a catchment area of approximately 360,000 inhabitants. The information collected included patient demographics, stage, grade and anatomical site of the cancer. The sites of CRC were determined from the surgical description and the pathology report and classified according to the International Statistical Classification of Diseases (ICD) $10^{\text {th }}$ revision. In order to compare results with previous reports three subsites were defined and analyzed: colon (the caecum, ascending colon, hepatic flexure, transverse colon, splenic flexure and descending colon), sigmoid colon (sigmoid and rectosigmoid junction) and rectum. We used a broad definition to categorize the proximal (descending colon and above), and distal segments of colon because current data indicate that subsites within sigmoid colon have characteristics similar to rectal-type cancers rather than proximal-colon cancers.

TNM staging was based on the operative findings and the histopathological report. Histological grade was recorded as well, moderately, or poorly differentiated.

Comparison data for Australia-wide patterns of CRC were obtained from the Australian Association of Cancer Registries (AACR) for the year 2003, most recent available. These included data on 12,536 CRC patients analyzed on the same lines as ours. Unfortunately, AACR does not provide data concerning TNM staging. Therefore, such analysis was performed for our study population only.

To examine trends in HRT use data were obtained from the Pharmaceutical Benefits Scheme and Repatriation Pharmaceutical Benefits Scheme databases (Medi- care Australia PBS Statistics), as well as from the annual Australian statistics on medicines reports. The latter use a combination of PBS data and survey data from a sample of community pharmacies.

For statistical evaluation data were presented as a number of cases and percentages with $95 \%$ confidence intervals (CI), chi-square and Fisher exact test were used for statistical analysis of these. Quantitative normally distributed data were expressed as means and standard deviation (SD) and Student's t-test was used for comparing mean values. Two-tailed $\mathrm{P}$ value was considered significantly at $<0.05$ level.

\section{RESULTS}

Of 145 patients with CRC admitted to our hospital in the 2 year period there were $65(44.8 \%)$ females with a mean age of $63.0 \pm 12.7$ years and $80(55.2 \%)$ males with a mean age of $67.3 \pm 11.4$ years. Colon cancer was diagnosed in 58 patients ( 32 females), sigmoid in 36 (16 females) and rectal in 51 (17 females). In our series there was a more distal distribution of CRC comparing with that seen previously in the Australian population: the proportion of rectal $(35.2 \%$ vs $26.9 \%, p=0.032)$ and sigmoid cancers $(24.8 \%$ vs $8.1 \% ; \mathrm{p}=0.003)$ was significantly higher and the proportion of colon cancers $(40 \%$ vs $65 \%, p=0.001)$ was significantly lower. The distal colon (sigmoid and rectal) was the most common site of carcinomas contributing $55.9 \%$ of all cases (50.8\% in females and $67.5 \%$ in males). The ratio of proximal to distal cancers was 0.67 in our series and 1.85 in the previous report.

The age-distribution pattern was similar in both studied periods with CRC rare before the age of 30 , significant increase after the age of 45 until 75-79 and decline thereafter. But the 2006-2007 data revealed a marked shift to the younger age most pronounced in females. Our cohort overall was on average 4 years younger $(\mathrm{p}=$ 0.001 ), and the females were 7.3 years younger than previously reported $(p<0.001)$ (Table 1). The difference was statistically significant in females with colon and rectal cancers, while no differences were observed in males for any cancer site. In our series females with rectal cancer were the youngest, they were on average 7.9 years younger than previously reported and 3.8 years younger than males with rectal cancer.

The total male/female $(\mathrm{M} / \mathrm{F})$ ratio in our series was the same as reported previously (1.23 and 1.21 , respectively). As indicated in Table 1, in both studied periods the $\mathrm{M} / \mathrm{F}$ ratio increased markedly from colon through the rectum site. However, our series demonstrated that, comparing with the previously described, the $\mathrm{M} / \mathrm{F}$ ratio was significantly lower in colon cancer patients $(0.81$ vs 
Table 1. Comparison of mean age (years \pm SD) of CRC patients in two studied periods by gender and site distribution of carcinomas.

\begin{tabular}{|c|c|c|c|c|c|}
\hline \multirow{2}{*}{ Period } & \multirow{2}{*}{ Gender } & \multirow{2}{*}{ All Patients } & \multicolumn{3}{|c|}{ Cancer Site } \\
\hline & & & Colon & Sigmoid & Rectal \\
\hline 2003 & \multirow{2}{*}{ Females } & $70.3 \pm 13.01$ & $71.4 \pm 12.56$ & $67.7 \pm 13.09$ & $67.8 \pm 13.83$ \\
\hline 2006-2007 & & $63.0 \pm 12.68^{* * *}$ & $63.9 \pm 14.16^{* * *}$ & $64.4 \pm 12.63$ & $59.9 \pm 9.54 * * *$ \\
\hline 2003-2004 & \multirow{2}{*}{ Males } & $68.8 \pm 11.56$ & $69.9 \pm 11.27$ & $67.7 \pm 10.92$ & $66.9 \pm 11.42$ \\
\hline 2006-2007 & & $67.3 \pm 11.38$ & $72.1 \pm 9.37$ & $67.3 \pm 9.24$ & $63.7 \pm 12.74$ \\
\hline 2003 & Both & $69.5 \pm 12.26$ & $70.6 \pm 11.97$ & $67.7 \pm 11.91$ & $67.2 \pm 12.68$ \\
\hline $2006-2007$ & Genders & $65.4 \pm 12.13^{* * *}$ & $67.6 \pm 12.82 *$ & $66.0 \pm 10.81$ & $62.4 \pm 11.81^{* * *}$ \\
\hline 2003 & Male/Female & 1.21 & 1.06 & 1.30 & 1.64 \\
\hline 2006-2007 & Ratio & 1.23 & 0.81 & 1.25 & 2.00 \\
\hline
\end{tabular}

$* * * \mathrm{p}<0.001, * \mathrm{p}<0.05$

$1.06)$ and higher in rectal cancer patients (2.00 vs 1.64$)$, indicating that the proportion of males with distal cancers is increasing. The ratio of proximal to distal cancers in females was 0.97 in our series and 2.30 in the previous report and in males 0.48 and 1.57 respectively, again suggesting a pronounced shift to distal cancer sites especially in males.

In our cohort, patients $<50$ years of age comprised $12.4 \%(18.5 \%$ females and $7.5 \%$ males $),<55$ years of age $20.0 \%$ (30.8\% and $11.3 \%$ respectively), $<60$ years of age $33.1 \%$ (41.5\% and $26.3 \%$ respectively). In 2003 the corresponding figures were $6.9 \%(7.8 \%$ and $6.2 \%)$, $12.9 \%(13.8 \%$ and $12.3 \%)$ and $21.4 \% \quad(21.2 \%$ and $21.7 \%$ ). The proportions of younger patients with CRC by gender and cancer site are given in Figure 1. In the recent series the proportion of patients with CRC younger than 50,55 or 60 years of age was significantly higher than previously reported due to a 2-fold increase in the proportion of younger females with cancers at all sites except sigmoid. In our cohort, among females with colon cancer $31.3 \%$ were aged $<55$ years and $37.5 \%$ were aged $<60$ years. Corresponding figures in the previous report were $11.6 \%$ and $17.9 \%$. Similarly in our series, among females with rectal cancer $35.3 \%$ were $<$ 55 years of age and $64.7 \%$ were $<60$ years of age, while previously this has been observed only on $19.1 \%$ and 28.9 , respectively.

The prevalence of advanced clinicopathological features of CRC in our younger patients is presented in Table 2. A significant proportion of patients with locally advanced $\mathrm{T} 3$ and $\mathrm{T} 4$ cancers were younger than 55 years of age (25\% females and $13.3 \%$ males). Importantly, most of patients $<55$ years of age were in T3 and T4 categories (12 of 20 females and 8 of 9 men). This age group contributed to $1 / 3$ of all females and $1 / 5$ of all males with lymph nodes metastasis and/or poor differentiation. The frequency of node metastasis was significantly higher in females than in males. $(p=0.018)$. Subjects younger than 60 years of age comprised from $1 / 3$ to about $1 / 2$ of all patients with advanced and/or unfavorable CRC.

Figure 2 presents the proportion of females with CRC in 5 year age groups in the recent series and in Australia in 2000 and 2003. The age-distribution patterns in 2000 and 2003 were similar, while in 2006-2007 there was a significant increase in proportion of females aged 45 to 59. This age group comprises the majority of women who use HRT.

Figure 3 displays the combined number of prescriptions for Premarin and Depo-premarin (most frequently prescribed HRT drugs) in Australia and Victoria over a 10-year period (financial years 1997/8-2006/7). The number of prescriptions peaked in 1999 and has declined since 2001. In Australia the total number of prescriptions for these drugs dropped in 2002 by $30.7 \%$ compared with the previous year and by $54.1 \%$ in 2006 ; in Victoria the corresponding figures were $32.4 \%$ and $55.4 \%$ respectively. These data are comparable with $40 \%$ drop in the number of total HRT prescriptions among conces-

Table 2. Proportion (\%, 95\% confidence interval) of younger subjects among patients with advanced CRC (2006-2007).

\begin{tabular}{cccc}
\hline $\begin{array}{c}\text { Age } \\
\text { (years) }\end{array}$ & Total & Females & Males \\
\hline \multicolumn{4}{c}{ T3/T4 stage } \\
$<\mathbf{5 5}$ & $\mathbf{1 8 . 5}$ & $\mathbf{2 5 . 0}$ & $\mathbf{1 3 . 3}$ \\
& $(11.7-27.1)$ & $(13.6-39.6)$ & $(5.9-24.6)$ \\
$<\mathbf{6 0}$ & $\mathbf{3 2 . 4}$ & $\mathbf{3 5 . 4}$ & $\mathbf{3 0 . 0}$ \\
& $(23.7-42.1)$ & $(22.2-50.5)$ & $(18.8-43.2)$ \\
\hline \multicolumn{4}{c}{ N1/N2 } \\
$<\mathbf{5 5}$ & $\mathbf{2 5 . 0}$ & $\mathbf{3 4 . 6}$ & $\mathbf{1 6 . 7}$ \\
& $(14.4-38.4)$ & $(17.2-55.7)$ & $(5.6-34.7)$ \\
$<\mathbf{6 0}$ & $\mathbf{3 5 . 7}$ & $\mathbf{4 2 . 3}$ & $\mathbf{3 0 . 0}$ \\
& $(23.4-49.6)$ & $(23.4-63.1)$ & $(14.7-49.4)$ \\
\hline \multicolumn{5}{c}{ Poor Differentiation } \\
$<\mathbf{5 5}$ & $\mathbf{2 9 . 0}$ & $\mathbf{3 3 . 3}$ & $\mathbf{2 3 . 1}$ \\
& $(14.2-48.0)$ & $(13.3-59.0)$ & $(5.0-53.8)$ \\
& $\mathbf{3 8 . 7}$ & $\mathbf{4 4 . 4}$ & $\mathbf{3 0 . 8}$ \\
& $(21.8-57.8)$ & $(21.5-69.2)$ & $(9.1-61.4)$ \\
\hline
\end{tabular}




\section{$<55$ years of age}
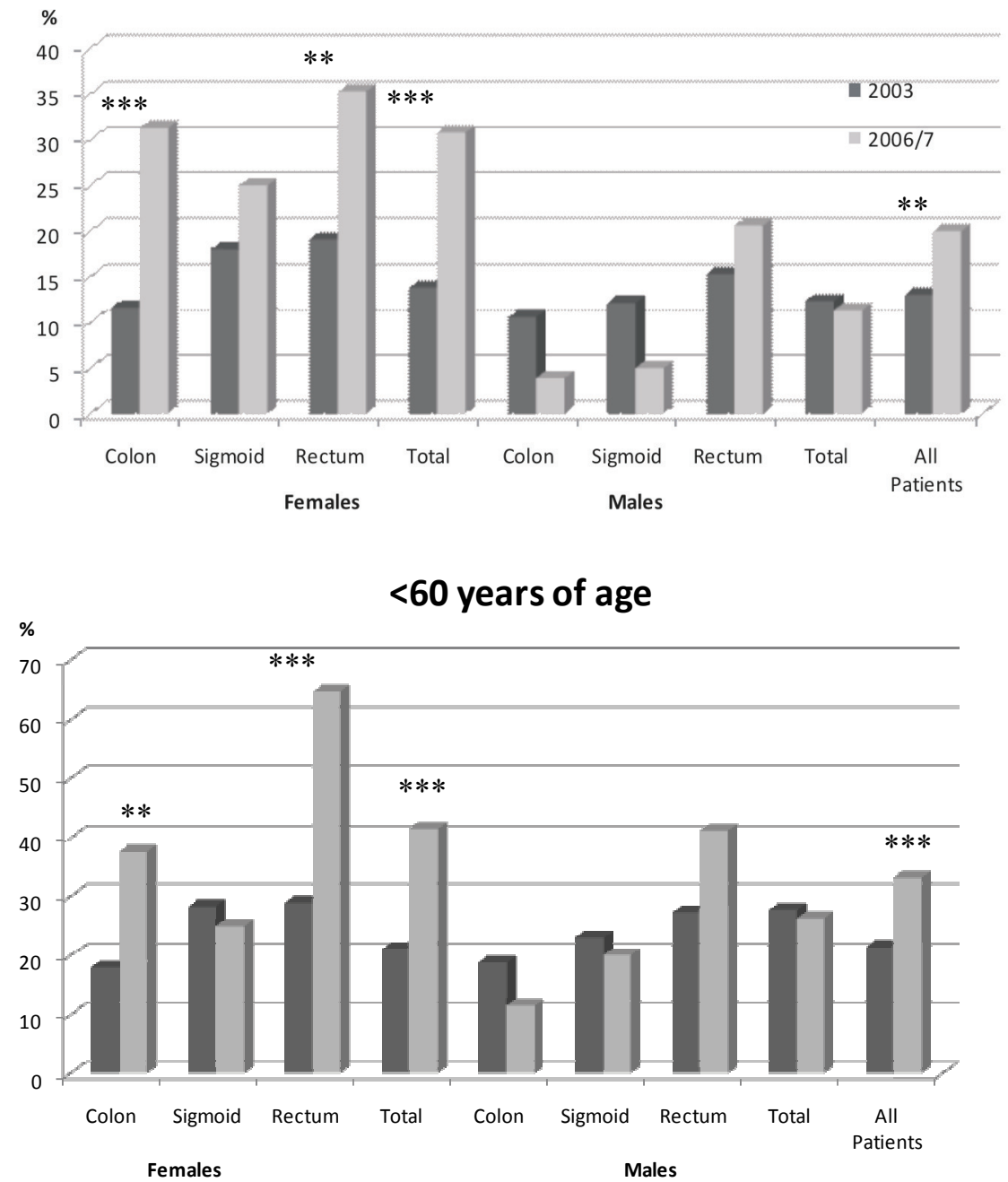

Figure 1. Proportion (\%) of younger patients with CRC in two study periods by gender and cancer site. ${ }^{* *} \mathrm{p}<0.001, * * \mathrm{p}<0.01$.

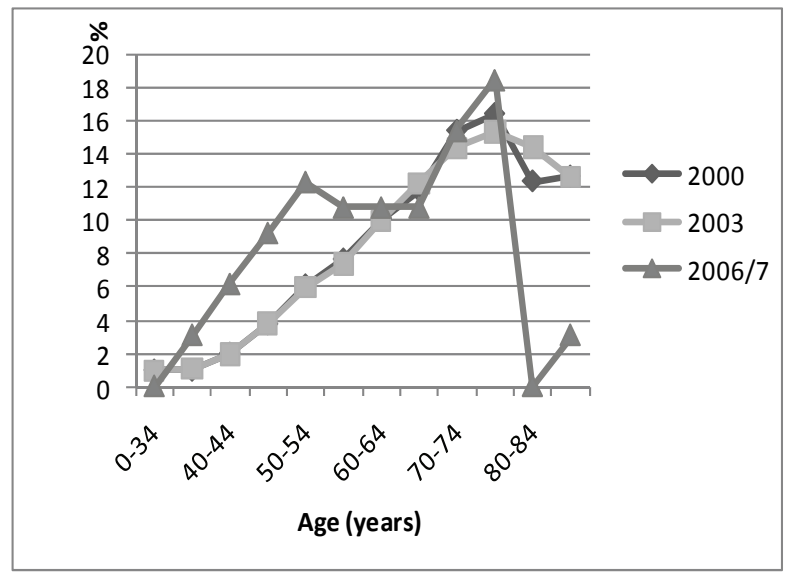

Figure 2. Age-distribution patterns of CRC in females in Australia in 2000 and 2003 and in our series 2006-2007.

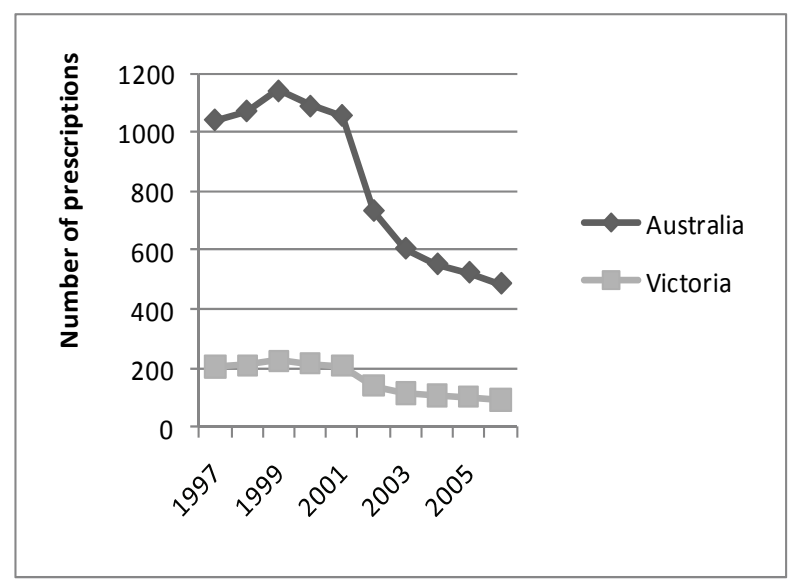

Figure 3. Prescriptions for Premarin and Depo-provera (combined data) in Australia and Victoria, 1997-2006.

Openly accessible at http://www.scirp.org/journal/HEALTH/ 
sion cardholders in Australia from 2001 to 2003. In this period a similar decline was observed in prescriptions for estrogen-only preparations (39\% decrease), and combined estrogen-progestogen preparations $(-41 \%)$ [22].

\section{DISCUSSION}

Our study indicates a change in pattern of CRC occurrence in 2006-2007. Compared with Australian data for 2003 our experience is of more distal cancers, greater proportion of younger patients, especially females, with high prevalence of more advanced and aggressive tumors. Several potential explanations for the changes in CRC characteristics observed in our study should be considered.

Cancers of proximal and distal colon might differ in their genetic nature, oncofetal antigen expression and evolve through different pathways and may be associated with distinct risk factors [6,23-29]. Proximal tumors compared to distal ones have a higher proportion of DNA microsatellite instability cancers, are more common in women and older patients. Risk factors for these include high intake of red meat and animal fat, low consumption of vegetables and fiber, sedentary life style, obesity and lower socioeconomic status. Alcohol consumption and smoking [30-32], use of aspirin and nonsteroidal anti-inflammatory drugs (NSAID) [33-35] and especially postmenopausal HRT use [15,19,20,36-40] have also an important influence on CRC risk. Although we cannot fully evaluate the possible effects of all the mentioned risk factors for $\mathrm{CRC}$, it seems unlikely that considerable changes in dietary and lifestyle habits occurred in our population between 2003 and 2006-2007. However, one variable which may be relevant, namely, a substantial reduction in HRT use, is obvious. In Australia and Victoria after 2001 prescriptions of Premarin and Depo-provera fell by a third in 2002 and by a half in 2006. A similar rapid and substantial drop in total HRT prescriptions from 2001 to 2003 was reported in Australia and New Zealand [22]. Age and gender-related changes in anatomical subsite CRC distribution observed in our study may be attributed, at least in part, to reduced HRT use after 2001. If hormonal factors protect against CRC then the reduced use of HRT should be accompanied by an increase in colon cancers in women during early postmenopausal period, as HRT use is associated mainly with reduced risk of colon cancer [14,15,20, $37,41]$. Our experience is consistent with such expectations.

This study comparing with previous Australian data clearly demonstrated three points: only females with CRC were significantly younger (on average 7.5 years), there was a substantial increase in proportion of females aged 45 to 59 years who comprise the majority of HRT users and the male predominance in colon cancer was reversed $(\mathrm{M} / \mathrm{F}$ ratio for colon cancer was 0.81 in 20062007 whereas 1.06 in 2003). Notably, the majority of our younger patients had aggressive and advanced CRC. Previous studies indicated that decrease in estrogen level after menopause increases the risk of a colon cancer with poorer differentiation $[11,42]$. Our findings are in line with the assumption of an approximate 3-5 year time lag between decrease in HRT use and its impact on CRC incidence rate $[21,43,44]$. In the Women's Health Initiative (WHI) trial the 38\% lower risk of CRC observed in women prescribed HRT during the trial phase disappeared within 3 years of discontinuing HRT [43].

Numerous epidemiological and experimental studies suggested a favorable influence of HRT on CRC risk. It was estimated that estrogens alone or in combination with progestins reduce colon risk by $20-44 \%$ in postmenopausal women, and the duration of HRT did not influence risk estimates [19-21]. In the present study a sharp drop in the HRT use after 2001 was associated with $20.1 \%$ increase in the proportion of females $<60$ years of age with CRC compared to the 2003 data. If this association is causal a further increase in CRC female patients should be expected. Of interest, the substantial decrease in HRT use was associated with a decline of breast cancer incidence in Australia, US and other countries $[22,45,46]$. The protective effects of estrogen on colonic carcinogenesis are mediated predominately through estrogen receptor $\beta$ (ER- $\beta$ ) involving both genomic and non-genomic mechanisms [40]. ER- $\beta$-knockout mice demonstrate hyperproliferation, loss of differentiation and disordered apoptosis of colonic mucosa, as well as disorganization of mucin localization, reduction in the number of hemidesmosomes and loss of tight junctions of colonic epithelium [47], indicating that ER$\beta$ plays a pivotal role in maintenance of cellular homeostasis in the colon. ER- $\beta$ is the dominant receptor in human colonic mucosa and seems to be essential for preventing malignant transformation of colonic epithelial cells. A significant reduction of ER- $\beta$ expression has been shown in colon adenocarcinoma cells and this correlated with tumor dedifferentiation, stage and grade $[42,48,49]$. Moreover, in the pre-malignant phase of colon carcinogenesis ER- $\beta$ expression is also reduced and inversely correlates with increase of proliferative activity in the adenomatous tissue [50]. It has been shown previously that methylation associated inactivation of estrogen receptor gene in ageing colorectal mucosa is one of the earliest events predisposing to cancerogenesis [51]. Other postulated mechanisms by which HRT use might reduce $\mathrm{CRC}$ risk include the influence of estrogens on bile acids [52,53], insulin and glucose control [54]. 
Our findings may have important practical implications for present and future screening strategies, treatment and prevention of CRC. Early diagnosis of CRC could improve survival. Currently CRC screening in Australia is advocated for people aged 55 and older. However, in our series patients younger than 55 years comprise $20 \%$ (females $31 \%$, males $11 \%$ ), suggesting that the optimal cut-off age for screening needs to be reviewed. Although we observed a distal shift of CRCs, in $40 \%$ of our patients (in $49.8 \%$ of females and in $30.6 \%$ of males) the cancers were located above the sigmoid colon. These tumors will be missed if sigmoidoscopy (not total colonoscopy) is chosen as the screening technique. The significant and rising number of rectal cancers $(35.2 \%$ in total, $26.2 \%$ in females and $42.5 \%$ in males) is likely to increase demand for radiotherapy services. The observed association between the changing age and subsite patterns of CRC in females and the drop in HRT use in the context of current data on estrogen effects on growth, differentiation and functioning of epithelial cells in the colon and the protective role of estrogen in CRC may stimulate research of novel preventive and therapeutic approaches such as development of selective ER- $\beta$ agonists. At present, the well established risks of traditional HRT [21] preclude its use to reduce the CRC in postmenopausal women [20]. However consumption of soy products and dietary fiber which are high in phyto-estrogens demonstrate a protective effect in CRC $[55,56]$ and are not associated with breast cancer [57]. Of note, the re-analysis of the WHI data showed that women who started estrogen therapy at the age of 50-59 years and continued it for 6-7 years did not have an increased risk of coronary heart disease [58], and have a decreased risk of early-stage breast cancer and a decreased risk of ductal carcinomas when compared with placebo treated women, although the risk of stroke in the estrogen group was non-significantly elevated [59]. These data together with significantly decreased incidence of colon cancer and fractures with long-term HRT use indicate the potential benefits of HRT. However, additional large controlled studies are needed to find definitive criteria for HRT use-time of initiation (? menopause) and duration (? 5-6 years) of therapy - to have beneficial effects on women's health, including protection against $\mathrm{CRC}$ and to avoid adverse effect.

Some limitations of this study warrant consideration. Our study was a single hospital-based. We were not able to calculate true incidence rates and therefore the comparisons with previous report were performed using proportions of CRC patients in age and subsite categories. The observation that sharp decrease in HRT use was followed by changes in CRC patterns in females does not establish causal relationship between the two, but provides a logical explanation and is of importance to public health.

\section{CONCLUSIONS}

Our series of CRCs in 2006-2007 show important age-, gender- and subsite-related changed in CRC patterns compared with those seen in the Australian population previously (2003). Of greatest concern is a significantly higher proportion of patients aged $<55$ and $<60$ years of age $(20 \%$ and $33 \%$ respectively), especially females (31\% and $41.5 \%)$. Furthermore, there were more female patients with colon cancer and younger patients were more likely to have more advanced and aggressive cancers. These findings seem to be temporally, and possibly causatively, related to decrease in HRT use and may have significant implications for effective screening strategies, provision of radiotherapy services and further research in CRC pathogenesis and prevention.

\section{REFERENCES}

[1] Australian Institute of Health and Welfare (AIHW) and Australasian Association of Cancer Registries (AACR). (2007) Cancer in Australia: An overview 2006. Cancer Series, AIHW, Canberra, 2007, 37.

[2] Chu, K.C., Tarone, R.E., Chow, W.H., Hankey, B.F. and Ries, L.A. (1994) Temporal patterns in colorectal cancer incidence, survival and mortality from 1950 through 1990. Journal of the National Cancer Institute, 86(13), 997-1006.

[3] Nelson, R.L., Persky, V. and Turyk, M. (1999) Determination of factors responsible for the declining incidence of colorectal cancer. Diseases of the Colon \& Rectum, 42(6), 741-752.

[4] Boyle, P. and Leon, M.E. (2002) Epidemiology of colorectal cancer. British Medical Bulletin, 64, 1-25.

[5] Rabeneck, L., El-Serag, H.B., Davila, J.A. and Sandler, R. S. (2003) Outcomes of colorectal cancer in the United States: no change in survival (1986-1997). American Journal of Gastroenterology, 98(2), 471-477.

[6] Gupta, A. K., Melton, L.J., Petersen, G.M., Timmons, L. J., Vege, S.S., Harmsen, W.S., Diehl, N.N., Zinsmeister, A.R. and Ahlquist, D.A. (2005) Changing trends in the incidence, stage, survival, and screen-detection of colorectal cancer: A population-based study. Clinical Gastroenterology and Hepatology, 3(2), 150-158.

[7] Cress, R.D., Morris, C., Ellison, G.L. and Goodman, M. T. (2006) Secular changes in colorectal cancer incidence by subsite, stage at diagnosis, and race/ethnicity, 1992- 2001. Cancer, 107(5), 1142-1152.

[8] Koo, J. H., Jalaludin, B., Wong, S.K., Kneebone, A., Connor, S.J. and Leong, R.W. (2008) Improved survival in young women with colorectal cancer. American Journal of Gastroenterology, 103(6), 1488-1495.

[9] Singh, H., Demers, A.A., Xue, L., Turner, D. and Bernstein, C.N. (2008) Time trends in colon cancer incidence and distribution and lower gastrointestinal endoscopy 
utilization in Manitoba. American Journal of Gastroenterology, 103(5), 1249-1256.

[10] Wu, X., Cokkinides, V., Chen, V.W., Nadel, M., Ren, Y., Martin, J. and Ellison, G.L. (2006) Associations of subsite-specific colorectal cancer incidence rates and stage of disease at diagnosis with county-level poverty, by race and sex. Cancer, 107(5), 1121-1127.

[11] Liang, W. (2007) Age, sex and the risk of grade-specific second primary colorectal cancer: Evidence for the protective effect of female hormone. European Journal of Cancer, 43(12), 1856-1861.

[12] Ferlay, J., Autier, P., Boniol, M., Heanue, M., Colombet, M. and Boyle, P. (2007) Estimates of the cancer incidence and mortality in Europe in 2006. Annals of Oncology, 18(3), 581-592.

[13] Crandall, C.J. (1999) Estrogen replacement therapy and colon cancer: A clinical review. Journal of Women's Health and Gender-Based Medicine, 8(9), 1155-1166.

[14] Paganini-Hill, A. (1999) Estrogen replacement therapy and colorectal cancer risk in elderly women. Diseases of the Colon \& Rectum, 42(10), 1300-1305.

[15] Nanda, K., Bastian, L.A., Hasselblad, V. and Simel, D.L. (1999) Hormone replacement therapy and the risk of colorectal cancer: A meta-analysis. Obstetrics \& Gynecology, 93(5), 880-888.

[16] Di Leo, A., Messa, C., Cavallini, A. and Linsalata, M. (2001) Estrogens and colorectal cancer. Current Drug Targets -Immune, Endocrine \& Metabolic Disorders, 1(1), $1-12$

[17] Gambacciani, M., Monteleone, P., Sacco, A. and Genazzani, A.R. (2003) Hormone replacement therapy and endometrial, ovarian and colorectal cancer. Best Practice \& Research Clinical Endocrinology \& Metabolism, 17(1), 139-147.

[18] Hoffmeister, M., Raum, E., Krtschil, A., Chang-Claude, J. and Brenner, H. (2009) No evidence for variation in colorectal cancer risk associated with different types of postmenopausal hormone therapy. Clinical Pharmacology \& Therapeutics, 86(4), 416-424.

[19] Grodstein, F., Newcomb, P.A. and Stampfer, M.J. (1999) Postmenopausal hormone therapy and the risk of colorectal cancer: A review and meta-analysis. American Journal of Medicine, 106(5), 574-582.

[20] Chlebowski, R.T., Wactawski-Wende, J., Ritenbaugh, C., Hubbell, F.A., Ascensao, J., Rodabough, R.J., Rosenberg, C.A., Taylor, V.M., Harris, R., Chen, C., Adams-Campbell, L.L. and White, E. (2004) Estrogen plus progestin and colorectal cancer in postmenopausal women. The New England Journal of Medicine, 350(10), 991-1004.

[21] Nelson, H.D., Humphrey, L.L., Nygren, P., Teutsch, S.M. and Allan, J.D. (2002) Postmenopausal hormone replacement therapy: Scientific review. JAMA, 288(7), 872-881.

[22] Canfell, K., Banks, E., Moa, A.M. and Beral, V. (2008) Decrease in breast cancer incidence following a rapid fall in use of hormone replacement therapy in Australia. Medical Journal of Australia, 188(11), 641-644.

[23] Lindblom, A. (2001) Different mechanisms in the tumorigenesis of proximal and distal colon cancers. Current Opinion in Oncology, 13(1), 63-69.

[24] Cheng, X., Chen, V.W., Steele, B., Ruiz, B., Fulton, J., Liu, L., Carozza, S.E. and Greenlee, R. (2001) Sub- site-specific incidence rate and stage of disease in colorectal cancer by race, gender, and age group in the United States, 1992-1997. Cancer, 92(10), 2547-2554.

[25] Iacopetta, B. (2002) Are there two sides to colorectal cancer? International Journal of Cancer, 101(5), 403408.

[26] Giovannucci, E., Pollak, M., Liu, Y., Platz, E.A., Majeed, N., Rimm, E.B. and Willett, W.C. (2003) Nutritional predictors of insulin-like growth factor I and their relationships to cancer in men. Cancer Epidemiology, Biomarkers \& Prevention, 12(2), 84-89.

[27] Matanoski, G., Tao, X.G., Almon, L., Adade, A.A. and Davies-Cole, J.O. (2006) Demographics and tumor characteristics of colorectal cancers in the United States, 1998-2001. Cancer, 107(5), 1112-1120.

[28] Azzoni, C., Bottarelli, L., Campanini, N., Di Cola, G., Bader, G., Mazzeo, A., Salvemini, C., Morari, S., Di Mauro, D., Donadei, E., Roncoroni, L., Bordi, C., and Sarli, L. (2007) Distinct molecular patterns based on proximal and distal sporadic colorectal cancer: Arguments for different mechanisms in the tumorigenesis. International Journal of Colorectal Disease, 22(2), 115-126.

[29] Leopoldo, S., Lorena, B., Cinzia, A., Gabriella, D.C., Angela Luciana, B., Renato, C., Antonio, M., Carlo, S., Cristina, P., Stefano, C., Maurizio, T., Luigi, R., and Cesare, B. (2008) Two subtypes of mucinous adenocarcinoma of the colorectum: clinicopathological and genetic features. Annals Of Surgical Oncology, 15(5), 14291439.

[30] Cho, E., Smith-Warner, S.A., Ritz, J., van den Brandt, P.A., Colditz, G.A., Folsom, A.R., Freudenheim, J.L., Giovannucci, E., Goldbohm, R.A., Graham, S., Holmberg, L., Kim, D.H., Malila, N., Miller, A.B., Pietinen, P., Rohan, T.E., Sellers, T.A., Speizer, F.E., Willett, W.C., Wolk, A., and Hunter, D.J. (2004) Alcohol intake and colorectal cancer: a pooled analysis of 8 cohort studies. Annals of Internal Medicine, 140(8), 603-613.

[31] Moskal, A., Norat, T., Ferrari, P. and Riboli, E. (2007) Alcohol intake and colorectal cancer risk: A doseresponse meta-analysis of published cohort studies. International Journal of Cancer, 120(3), 664-671.

[32] Shrubsole, M.J., Wu, H., Ness, R.M., Shyr, Y., Smalley, W.E. and Zheng, W. (2008) Alcohol drinking, cigarette smoking, and risk of colorectal adenomatous and hyperplastic polyps. American Journal of Epidemiology, 167(9), 1050-1058.

[33] Smalley, W., Ray, W.A., Daugherty, J. and Griffin, M.R. (1999) Use of nonsteroidal anti-inflammatory drugs and incidence of colorectal cancer: A population-based study. Archives of Internal Medicine, 159(2), 161-166.

[34] Rostom, A., Dube, C., Lewin, G., Tsertsvadze, A., Barrowman, N., Code, C., Sampson, M. and Moher, D. (2007) Nonsteroidal anti-inflammatory drugs and cyclooxygenase-2 inhibitors for primary prevention of colorectal cancer: A systematic review prepared for the U.S. Preventive Services Task Force. Annals of Internal Medicine, 146(5), 376-389.

[35] Dube, C., Rostom, A., Lewin, G., Tsertsvadze, A., Barrowman, N., Code, C., Sampson, M. and Moher, D. (2007) The use of aspirin for primary prevention of colorectal cancer: a systematic review prepared for the U.S. Preventive Services Task Force. Annals of Internal 
Medicine, 146(5), 365-375.

[36] Hebert-Croteau, N. (1998) A meta-analysis of hormone replacement therapy and colon cancer in women. Cancer Epidemiology, Biomarkers \& Prevention, 7(8), 653-659.

[37] Prihartono, N., Palmer, J.R., Louik, C., Shapiro, S. and Rosenberg, L. (2000) A case-control study of use of postmenopausal female hormone supplements in relation to the risk of large bowel cancer. Cancer Epidemiology, Biomarkers \& Prevention, 9(4), 443-447.

[38] Nichols, H.B., Trentham-Dietz, A., Hampton, J.M. and Newcomb, P.A. (2005) Oral contraceptive use, reproductive factors, and colorectal cancer risk: Findings from Wisconsin. Cancer Epidemiology, Biomarkers \& Prevention, 14(5), 1212-1218.

[39] Murff, H.J., Shrubsole, M.J., Smalley, W.E., Wu, H., Shyr, Y., Ness, R.M. and Zheng, W. (2007) The interaction of age and hormone replacement therapy on colon adenoma risk. Cancer Detection and Prevention, 31(2), 161-165.

[40] Kennelly, R., Kavanagh, D.O., Hogan, A.M. and Winter, D.C. (2008) Oestrogen and the colon: Potential mechanisms for cancer prevention. Lancet Oncology, 9(4), 385391.

[41] Rizk, D.E., Helal, T.E., Mason, N. and Berg, B. (1998) Non-evidence of estrogen receptors in the rectal mucosa. International Urogynecology Journal and Pelvic Floor Dysfunction, 9(3), 136-139.

[42] Konstantinopoulos, P.A., Kominea, A., Vandoros, G., Sykiotis, G.P., Andricopoulos, P., Varakis, I., Sotiropoulou-Bonikou, G. and Papavassiliou, A.G. (2003) Oestrogen receptor beta (ERbeta) is abundantly expressed in normal colonic mucosa, but declines in colon adenocarcinoma paralleling the tumour's dedifferentiation. European Journal of Cancer, 39(9), 1251-1258.

[43] Heiss, G., Wallace, R., Anderson, G.L., Aragaki, A., Beresford, S.A., Brzyski, R., Chlebowski, R.T., Gass, M., LaCroix, A., Manson, J.E., Prentice, R.L., Rossouw, J. and Stefanick, M.L. (2008) Health risks and benefits 3 years after stopping randomized treatment with estrogen and progestin. JAMA, 299(9), 1036-1045.

[44] Chan, J.A., Meyerhardt, J.A., Chan, A.T., Giovannucci, E. L., Colditz, G.A. and Fuchs, C.S. (2006) Hormone replacement therapy and survival after colorectal cancer diagnosis. Journal of Clinical Oncology, 24(36), 56805686.

[45] Clarke, C.A. and Glaser, S.L. (2007) Declines in breast cancer after the WHI: Apparent impact of hormone therapy. Cancer Causes Control, 18(8), 847-852.

[46] Ravdin, P.M., Cronin, K.A., Howlader, N., Berg, C.D., Chlebowski, R.T., Feuer, E.J., Edwards, B.K. and Berry, D.A. (2007) The decrease in breast-cancer incidence in 2003 in the United States. The New England Journal of Medicine, 356(16), 1670-1674.

[47] Wada-Hiraike, O., Warner, M. and Gustafsson, J.A. (2006) New developments in oestrogen signalling in colonic epithelium. Biochemical Society Transactions, 34(6), 1114-1116.

[48] Foley, E.F., Jazaeri, A.A., Shupnik, M.A., Jazaeri, O. and Rice, L.W. (2000) Selective loss of estrogen receptor beta in malignant human colon. Cancer Research, 60(2), 245248.

[49] Jassam, N., Bell, S.M., Speirs, V. and Quirke, P. (2005) Loss of expression of oestrogen receptor beta in colon cancer and its association with Dukes' staging. Oncology Reports, 14(1), 17-21.

[50] Di Leo, A., Barone, M., Maiorano, E., Tanzi, S., Piscitelli, D., Marangi, S., Lofano, K., Ierardi, E., Principi, M. and Francavilla, A. (2008) ER-beta expression in large bowel adenomas: implications in colon carcinogenesis. Digestive and Liver Disease, 40(4), 260-266.

[51] Issa, J.P., Ottaviano, Y.L., Celano, P., Hamilton, S.R., Davidson, N.E. and Baylin, S.B. (1994) Methylation of the oestrogen receptor $\mathrm{CpG}$ island links ageing and neoplasia in human colon. Nature Genetics, 7(4), 536-540.

[52] McMichael, A.J. and Potter, J.D. (1980) Reproduction, endogenous and exogenous sex hormones, and colon cancer: A review and hypothesis. Journal of the National Cancer Institute, 65(6), 1201-1207.

[53] Alberts, D. S., Martinez, M.E., Hess, L.M., Einspahr, J.G., Green, S. B., Bhattacharyya, A. K., Guillen, J., Krutzsch, M., Batta, A. K., Salen, G., Fales, L., Koonce, K., Parish, D., Clouser, M., Roe, D., and Lance, P. (2005) Phase III trial of ursodeoxycholic acid to prevent colorectal adenoma recurrence. Journal of the National Cancer Institute, 97(11), 846-853.

[54] Saydah, S.H., Platz, E.A., Rifai, N., Pollak, M.N., Brancati, F.L. and Helzlsouer, K.J. (2003) Association of markers of insulin and glucose control with subsequent colorectal cancer risk. Cancer Epidemiology, Biomarkers \& Prevention, 12(5), 412-418.

[55] Adlercreutz, H. (2002) Phyto-oestrogens and cancer. Lancet Oncology, 3(6), 364-373.

[56] Hogan, A.M., Collins, D., Sheehan, K., Zierau, O., Baird, A.W. and Winter, D.C. (2010) Rapid effects of phytoestrogens on human colonic smooth muscle are mediated by oestrogen receptor beta. Molecular and Cellular Endocrinology, 320(1-2), 106-110.

[57] Hedelin, M., Lof, M., Olsson, M., Adlercreutz, H., Sandin, S. and Weiderpass, E. (2008) Dietary phytoestrogens are not associated with risk of overall breast cancer but diets rich in coumestrol are inversely associated with risk of estrogen receptor and progesterone receptor negative breast tumors in Swedish women. Journal of Nutrition, 138(5), 938-945.

[58] Rossouw, J.E., Prentice, R.L., Manson, J.E., Wu, L., Barad, D., Barnabei, V.M., Ko, M., LaCroix, A.Z., Margolis, K.L. and Stefanick, M.L. (2007) Postmenopausal hormone therapy and risk of cardiovascular disease by age and years since menopause. JAMA, 297(13), 14651477.

[59] Stefanick, M.L., Anderson, G.L., Margolis, K.L., Hendrix, S.L., Rodabough, R.J., Paskett, E.D., Lane, D.S., Hubbell, F.A., Assaf, A.R., Sarto, G.E., Schenken, R.S., Yasmeen, S., Lessin, L. and Chlebowski, R.T. (2006) Effects of conjugated equine estrogens on breast cancer and mammography screening in postmenopausal women with hysterectomy. JAMA, 295(14), 1647-1657. 